\title{
Neonectria ditissima conidium production and release in planta
}

\author{
Monika Walter ${ }^{1, \star}$, Charles E. Chevalier ${ }^{2}$, Lauren Turner ${ }^{1}$ and Rebecca E. Campbell ${ }^{1}$ \\ ${ }^{1}$ The New Zealand Institute for Plant \& Food Research, Old Mill Rd, RD3, Motueka 7198, New \\ Zealand \\ ${ }^{2}$ Ecole Nationale Supérieure d'Agronomie et des Industries Agroalimentaires (ENSAIA), 2 \\ Avenue de la Forêt de Haye, 54505 Vandoeuvre-lès-Nancy, France \\ ${ }^{*}$ Corresponding author: monika.walter@plantandfood.co.nz
}

\begin{abstract}
Neonectria ditissima, the causal agent of European canker in apples, conidia are available year-round in the Tasman region of New Zealand. Spore production and release in apple trees were quantified during natural and artificial rain events. Rain traps captured spores over 18 rain events (July-August 2017) from European canker lesions (excised and in planta) derived from 'Royal Gala' picking wound and rasp wound infections. Rain traps were monitored regularly to determine spore release over time. Differences in the number of conidia produced from lesions on the tree and excised lesions re-mounted in the tree were not significant. Lesions arising from picking wounds produced 7.2 times more spores on average than lesions arising from rasp wounds. Most spores were released within the first hour of rain and total spore release followed a logarithmic curve. Rain duration $\times$ volume of water determined the rate of conidia release. Excised lesions are suitable to study the effect of biotic and abiotic drivers on spore production.
\end{abstract}

Keywords Nectria galligena, Cylindrocarpon heteronema, spore release, spore production, European apple canker

\section{INTRODUCTION}

Neonectria ditissima (syn. Nectria galligena), the causal agent of European canker, can produce two types of spore, conidia and ascospores. In the Tasman district of New Zealand, both spore types are readily produced all year round in older lesions caused by wound infections in apple trees (Amponsah et al. 2017). Recent research has also shown that large wounds are more susceptible to infection (Amponsah et al. 2015; Walter et al. 2016). Spur lesions resulting from picking wound infections dominate in the Tasman apple-growing district followed by shoot lesions from leaf scar infections (Campbell et al. 2016). New Zealand Apple \& Pear Inc. (NZAP) best management guidelines (Tim Herman, NZAP, pers. comm.) advocate no less than four 'canker walks' per year to locate and remove damaged plant material. Removing such plant material should remove associated inoculum so very few lesions, if any, produce ascospores. In planta, perithecia are only produced on mature ( $>8$ month-old) cankers (Swinburne 1975; Weber 2014). Therefore, conidia are likely to be the main source of inoculum driving the disease epidemic within an orchard block. This hypothesis is validated by the spatial dynamics of the pathogen and the hot-spot dispersal of rainsplashed conidia shown by Dan et al. (1982) and Campbell et al. (2016). Conidium production potential also varies amongst cultivars (Walter et al. 2017), but little is known of the effect of lesion type (branch versus spur) and the effect of lesion sporulation in planta (non-excised) versus an excised lesion on spore production potential. The aim of this study was to investigate 
these differences and also determine the rate of conidium release during natural and simulated rain events.

\section{MATERIAL AND METHODS}

All experiments, unless otherwise specified, were conducted in 'Royal Gala' apple trees (planted in winter 2013; 'M9' rootstock) at the New Zealand Institute for Plant \& Food Research Limited (PFR) research orchard at Whakarewa Street, Motueka, New Zealand. Rain traps to collect conidia consisted of 75-mm diameter plastic funnels draining into $50-\mathrm{mL}$ Falcon tubes directly suspended (by craft wire) underneath young (3-6-week-old) European canker lesions. Branch lesions were created by artificially inoculating rasp wounds (Walter et al. 2016) on 1-year-old shoots during weekly $(n=6)$ inoculation in February-March 2017. At the same times, spur lesions were created by artificially inoculating fresh picking wounds as described by Walter et al. (2015). Inocula used consisted of wild-type spores, prepared on 31 January $2017\left(1 \times 10^{5}\right.$ conida/mL of water $)$ from sporulating lesions collected from 'Scilate' apple trees at a commercial property in Motueka and stored frozen $\left(-18^{\circ} \mathrm{C}\right)$ in Falcon tubes.

\section{Experiment 1}

In Experiment 1, rain traps were placed underneath lesions on 18 July 2017 . There were two lesion types (branch and spur arising from rasp and picking wound inoculations respectively during March 2017). Each lesion type featured in a single tree and was paired with a similar excised lesion (by type and size). The excised lesion was on an approximately $10-\mathrm{cm}$ long twig and resuspended with soft craft wire into the same tree and similar position as the in planta lesion. In total, there were 20 rain traps, five non-excised branch lesions, five excised branch lesions, five non-excised spur lesions and five excised spur lesions on ten randomly chosen trees, selected from 150 inoculated trees in a 4 row $\times 50$ tree setting. There were four or more buffer trees between the monitored trees from Experiment 1. All other branch sections with lesions were removed (used in Experiments 2, 3 and 4) from the trial site to prevent cross-contamination. Lesion length and diameter were measured at the onset (18 July 2017) using a digital calliper. Conidia were collected for a total of 18 rain events. For each rain event, rain water trapped was determined by weight and $N$. ditissima conidia counted using a haemocytometer. Generally, conidia could be counted without further concentration steps required. However, for low conidium concentrations, conidia were allowed to settle (for $>1 \mathrm{~h}$ ), the supernatant carefully removed by pipetting, leaving 3-5 mL water and spore deposit in the Falcon tube. Tubes were re-weighed, shaken and then conidia counted. Data were expressed as total conidia collected/lesion and conidia collected/mm lesion length.

\section{Experiment 2}

For Experiment 2, excised branch lesions with abundant sporodochia were bundled (five lesions/bundle). Lesion sizes within and between bundles were similar. The five bundles were suspended from an iron rod $1 \mathrm{~m}$ above the ground with rain traps directly underneath in an open area. Bundles were spaced approximately $25 \mathrm{~cm}$ apart on the $1.5-\mathrm{m}$ long rod. Falcon tubes were retrieved after $1-3 \mathrm{~mL}$ of rain capture during a natural rain event (8 August 2017). The amount of rain trapped in each Falcon tube and time required to do so were measured. A total of 22 samples were taken from each lesion bundle during $270 \mathrm{~min}$ of natural rain to determine the rate of conidium release.

\section{Experiments 3 and 4}

These were a repeat of Experiment 2 but using artificial rain in an open area and sporulating excised lesion bundles. Two fine-mist sprinklers (Coolnet Pro Sprinklers $1 \times 7.5 \mathrm{~L} / \mathrm{h}$, Think Water New Zealand, Motueka) were mounted at the edge of the iron rod. Rain traps were replaced at 5-10 min intervals (or 2-7 $\mathrm{mL}$ of artificial rain trapped in the Falcon tubes).

\section{Data analysis}

For Experiment 1, the estimate of total lesion 
area was difficult to calculate due to the different shapes of spur and branch lesions. Therefore, data were analysed as total number of conidia released and collected/lesion and as number of conidia released and collected $/ \mathrm{mm}$ lesion length. Relationships between factors were explored via correlation analyses and analysis of variance (ANOVA) using general linear model, Minitab 16.1.

For Experiments 2-4, conidium release was explored graphically by plotting total spore counts (actual values) and proportional spore counts (by determining the proportion of conidia at each assessment out of the total number of conidia released during the experiment per lesion bundle) for the 15 rain trap data (three experiments, five rain traps) against total exposure duration (time in min) and total rain water trapped (volume in $\mathrm{mL}$ ). Proportional spore counts were plotted against time $\times$ volume and regressed using a logarithmic function.

\section{RESULTS}

In Experiment 1, the average lesion length for picking (spur) and Experiments 1-4, rasp wound (branch) cankers were $16.6 \mathrm{~mm}$ (11.2-21.1 mm) and $21.2 \mathrm{~mm}(4.1-39.2 \mathrm{~mm})$, respectively; with an average lesion diameter of $9.0 \mathrm{~mm}$ (6.3-12.8 $\mathrm{mm})$ and $4.7 \mathrm{~mm}(3-7.2 \mathrm{~mm})$, respectively. Most of the branch lesions were $>80 \%$ ringbarked.

Total spore data (conidia/lesion) were highly correlated with total conidia/mm lesion $(\mathrm{r}=0.998)$; therefore, data are presented as conidia/mm lesion length. Similarly, data from the excised lesions and in planta lesions was highly correlated $(r=0.923)$ following the same release pattern, which was true for both lesion types (Fig. 1). More conidia were released from spur lesions compared with branch lesions during the monitoring period $(P<0.001)$. On average, for the 18 rain events monitored, the number of conidia produced on picking wounds was similar between excised (4273 conidia/mm lesion) and non-excised (3960 conidia/mm lesion) but was double for excised branch lesions (1093 conidia/ mm lesion) compared with non-excised branch lesions (544 conidia/mm lesion). However,

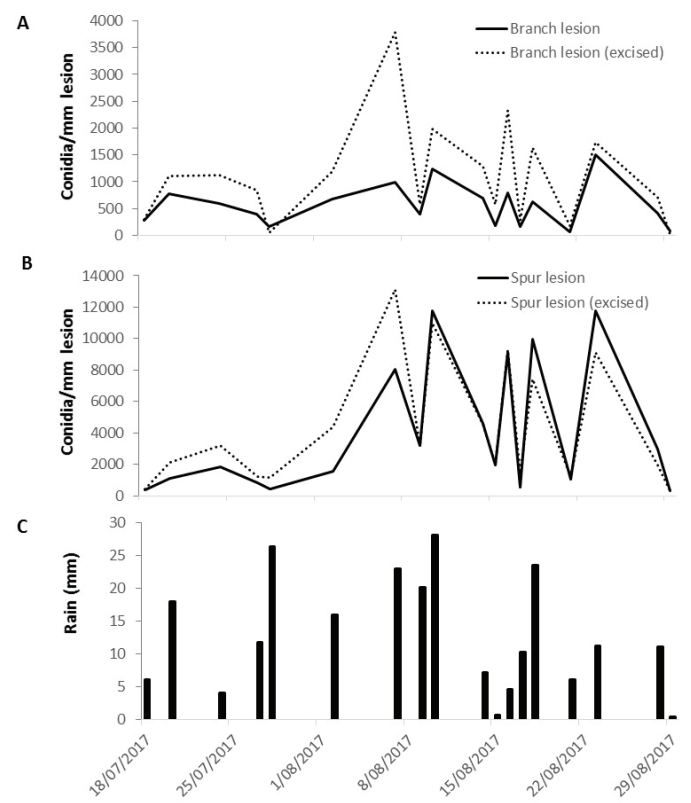

Figure 1 Neonectria ditissima conidia collected in rain traps during 18 rain events in July/ August 2018 in Tasman, released from European canker branch and spur lesions arising from rasp wound (A) and picking wound (B) infections, respectively, in 'Royal Gala' apple trees. Cut lesions from the trees were re-suspended in the trees with soft craft wire. The total amount of rain (C) for each rain event is also shown.

despite twice as many conidia being collected, there was no statistical difference $(\mathrm{P}=0.297)$ in spore release between excised and non-excised branch lesions.

In Experiment 2, it took 6 to 29 min to collect $1-3 \mathrm{~mL}$ of water in the rain traps underneath the lesion bundles during a natural rain event. Conidium release was low between 0 and $29 \mathrm{~min}$ while the wood became wet. After that, average total spore release followed a logarithmic pattern (Fig. 2) with most conidia released between the first 51-114 min of rain. Numbers of conidia collected slowed after this time but conidia continued to be recovered during the entire 270-min observation period. The logarithmic release pattern of spores was also observed in 


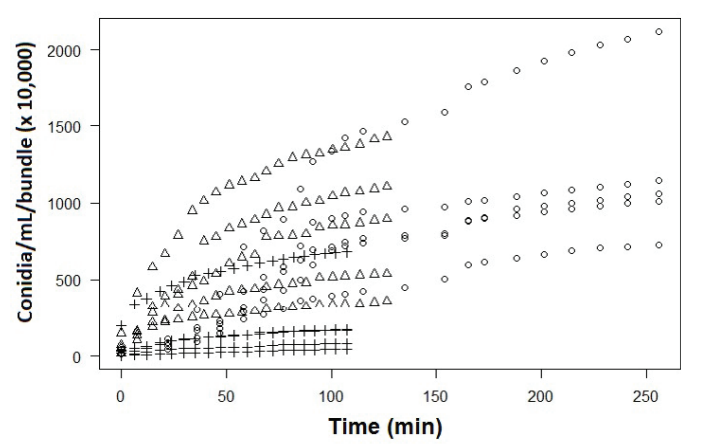

Figure 2 Experiment $2(\bigcirc), 3(\Delta)$ and $4(+)$, total Neonectria ditissima conidia release from sporulating European canker lesions per bundle $(n=5)$ during a $270-$, 136 - or 113-min exposure period, respectively. Experiment 2 was conducted in Tasman during a natural rain event on 8 August 2017, the others under artificial rain. Rain traps were changed after an average of: 1.7 $\mathrm{mL}$ (Experiment 2); $5.4 \mathrm{~mL}$ (Experiment 3); and $6.0 \mathrm{~mL}$ (Experiment 4) water (per trap) captured exposure period. Data adjusted to zero for the first-trap measurement.

Experiments 3 \& 4 (Fig. 2). The mist sprinklers however provided larger quantities of water, shortening the trapping intervals to $4-9 \mathrm{~min}$ and increasing the average amount of water in the rain traps to 5.4 and $6.0 \mathrm{~mL}$, respectively, per exposure period. Again, conidia were recovered continuously during the exposure period.

Adjusting actual conidium release (Fig. 2) in Experiments 2-4 to proportional conidium release clearly shows the similarity in dependence on exposure time (Fig. 3a) and total rain volume trapped (Fig. 3b). Proportional conidium release could be expressed by exposure time $\times$ rain volume trapped (Fig. 3c). This was modelled with a simple regression equation of:

Proportional release $=0.116 \mathrm{x} \log ($ time $[\mathrm{min}] \mathrm{x}$ volume $[\mathrm{mL}]+1)-0.146$

\section{DISCUSSION}

Using excised European canker lesions for experiments provides a realistic estimate on sporulation behaviour and potential of lesions in planta. Excised lesions, therefore, can be used to study the effect of biotic and abiotic drivers on spore production. The large difference in sporulation potential of spur lesions compared to young branch lesions was unexpected, but may be related to nutritional and plant-defence differences for the two tissue types. Further research will be required to understand the mechanisms governing conidiation in different types of $N$. ditissima apple lesions. For growers, the implication of picking wound infections is important. Picking wounds are very susceptible to infections (Amponsah et al. 2015; Alves \& Nunes 2017). Lesions arising from picking wound infections are harder to spot (dead short spurs as opposed to wilting branches from branch cankers), and, as shown here, provided 7.2 times the amount of conidia compared to the young branch lesions from rasp wounds. Fewer than 10 spores are required for infections of wounds (Walter et al. 2016) with wound susceptibility and subsequent chances of lesion development being highest for autumn/winter infections (Alves \& Nunes 2017). In New Zealand, conidia release also peaks in April, during apple fruit harvest (Amponsah et al. 2017).

It was possible to collect and count conidia directly using a small bundle of detached branch lesions without the need to further concentrate spores in rain traps. The observed decline in conidia release over time agrees with findings by Butt et al. (1994). They reported that conidia were present following $15 \mathrm{~min}$ of wetting (sampling in $15 \mathrm{~min}$ intervals) and also found that spore production potential varied between cankers of similar size and type. Conidia are readily waterborne and are released from sporodochia in the lesion as soon as these are wet (Amponsah et al. 2017). Wetness and/or high humidity are required for sporodochium and conidium formation (Swinburne 1975); therefore conidia release and production of new ones may happen simultaneously. It is clear from the data presented 

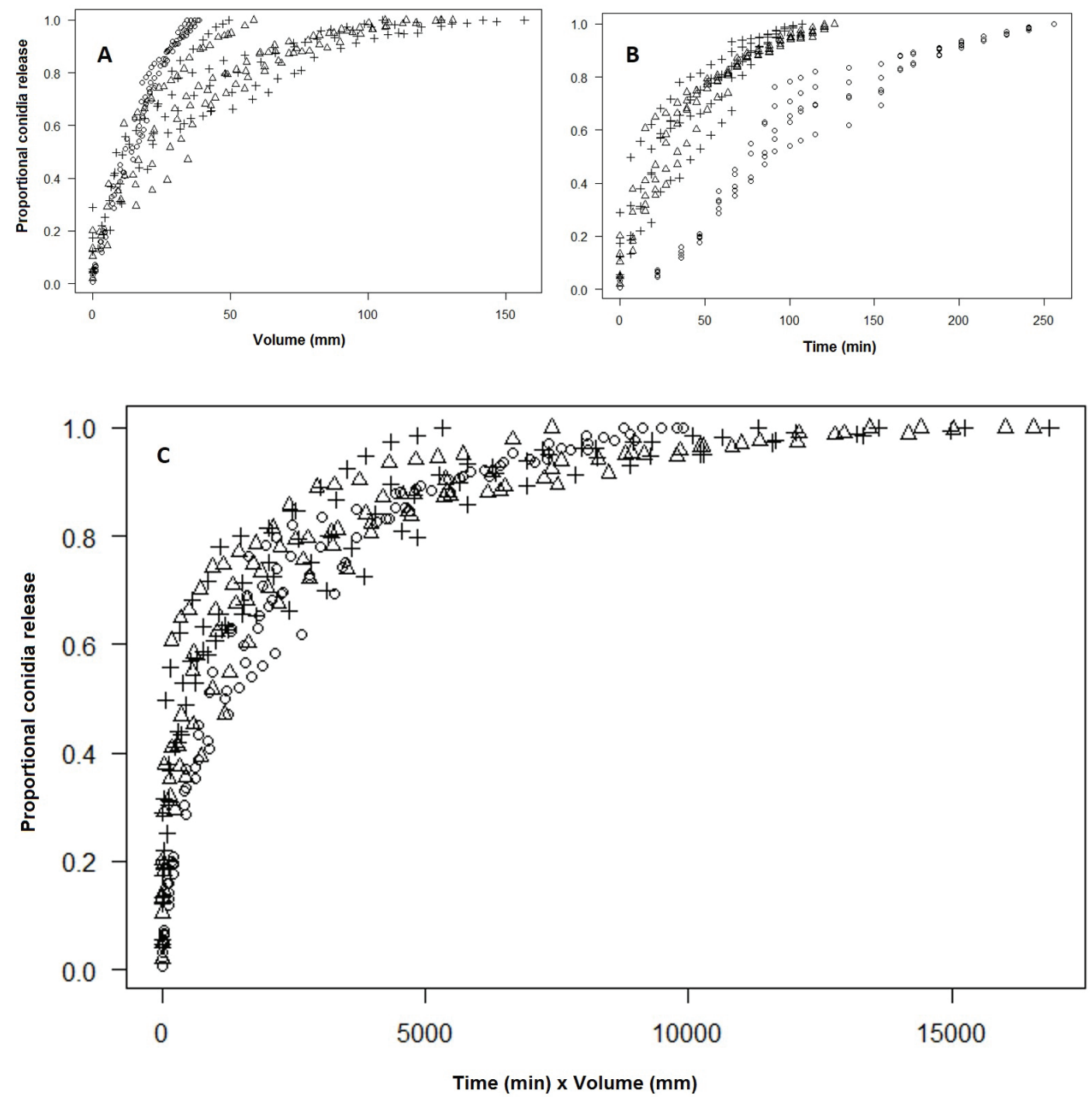

Figure 3 Experiment $2(\bigcirc), 3(\Delta)$ and $4(+)$, proportional Neonectria ditissima conidia release per bundle from sporulating European canker lesions $(n=5)$ during a 270-, 136- or 113-min exposure period in Tasman. A: Proportional conidia release over time; B: proportional conidia release by rain volume trapped; and C: Proportional conidia release over time $\times$ rain volume trapped. Data adjusted to zero for the first-trap measurement.

here that, following wetting of the canopy, the majority of conidia will be released during the first few hours of a rain event, subject primarily to the amount of rain impacting a lesion.

\section{ACKNOWLEDGEMENTS}

This research was funded by The New Zealand Institute of Plant and Food Research Limited. We thank Tim Herman (New Zealand Apple \& Pear Inc.) and Jason Smith (Horteye) for reviewing a draft of this manuscript. 


\section{REFERENCES}

Alves SAM, Nunes CC 2017. Seasonal susceptibility of apple trees to Neonectria ditissima wound infections. New Zealand Plant Protection 70: 73-77.

Amponsah NT, Walter M, Beresford RM, Scheper RWA 2015. Seasonal wound presence and susceptibility to Neonectria ditissima infection in New Zealand apple trees. New Zealand Plant Protection 68: 250-256.

Amponsah NT, Walter M, Scheper RWA 2017. Factors affection European canker spore release and availability in New Zealand apple orchards. New Zealand Plant Protection 70: 78-86.

Butt DJ, Gunn ND, Xu XM 1994. Release of Nectria galligena spores from apple cankers. Norwegian Journal of Agricultural Sciences. No 15 Supplement, 309-316.

Campbell RE, Roy S, Curnow T, Walter M 2016. Monitoring methods and spatial patterns of European canker disease in commercial orchards. New Zealand Plant Protection 69: 213-220.

Dan LJ, Doust JL, Eaton GW 1982. The effect of European canker and its spatial pattern on four apple cultivars in British Columbia. Journal of Applied Ecology 19: 603-609.

Swinburne TR 1975. European canker of apple. Review of Plant Pathology 54: 787-799.

Walter M, Campbell RE, Amponsah NT, Scheper RWA, Butler RC 2017. Evaluation of biological and agrichemical products for control of Neoncectria ditissima conidia production. New Zealand Plant Protection 70: 87-96.

Walter M, Roy S, Fisher BM, Mackle L, Amponsah NT, Curnow T, Campbell RE, Braun P, Reinecke A, Scheper RWA 2016. How many conidia are required for wound infection of apple plants by Neonectria ditissima? New Zealand Plant Protection 69: 238-245.

Walter M, Stevenson OD, Amponsah NT, Scheper RWA, Rainham D, Hornblow C, Kerer U, Dryden G, Latter I, Butler RC 2015. Control of Neonectria ditissima with copper based products in New Zealand. New Zealand Plant
Protection 68: 241-249.

Weber RWS 2014. Biology and control of the apple fungus canker Neonectria ditissima (syn. N. galligena) from a Northwestern European perspective. Ewerbs-Obstbau: https://doi.org/10.1007/s10341-014-0210-x. 